\title{
Polígonos de Voronoi como alternativa aos problemas das Áreas Mínimas Comparáveis: uma análise das mudanças populacionais na Região Norte do Brasil
}

\author{
Renilson Rodrigues da Silva* \\ Carlos José Caetano Bacha**
}

\begin{abstract}
Este artigo propõe uma metodologia alternativa para construção de Áreas Mínimas Comparáveis - $A M C$ e um método de ponderação de variáveis socioeconômicas para essas AMC. A análise empírica - em particular na área de economia - das mudanças populacionais, econômicas e sociais em nível municipal é tarefa razoavelmente complexa. Isso ocorre devido às constantes emancipações de distritos a partir do desmembramento de outros municípios. O método de agregação comumente utilizado segue a mesma lógica da divisão territorial, o qual gera viés nos testes estatísticos. Neste trabalho, propõe-se um método alternativo de construção de $A M C$, aplicando os Polígonos de Voronoi - PV e agregando os dados por ponderação. Para testar o método proposto, avaliaramse as mudanças populacionais ocorridas na Região Norte, entre 1980 e 2000, à luz da Nova Geografia Econômica - NGE, comparando-o com o método de AMC adotado pelo Ipea. O modelo de AMC com PV apresentou melhor ajustamento dos dados e coerência no comportamento das variáveis de acordo com a teoria. Com esse desempenho, trabalhos futuros que visem análises espaciais com o uso de PV, seguramente, deverão apresentar resultados mais satisfatórios, haja vista que por esta metodologia os dados são agrupados seguindo a lógica dos efeitos espaciais de vizinhança.
\end{abstract}

Palavras-chave: Polígonos de Voronoi. Áreas Mínimas Comparáveis. Análise espacial.

\section{Introdução}

Como analisar a alteração de uma variável socioeconômica de um município que foi desmembrado em três novos municípios? No Brasil, o estudo dessas variações, como é o caso de mudanças populacionais, é tarefa razoavelmente complexa. Isso ocorre devido às constantes emancipações de distritos a partir do desmembramento de um ou mais municípios. Assim, comparar o dinamismo econômico de um local em relação a outro, por exemplo, esbarra no problema supracitado. A solução encontrada é o uso de Áreas Mínimas Comparáveis - AMC, que consiste em agrupar os dados dos novos

\footnotetext{
* Doutorando pelo PPGEA/Universidade de São Paulo. Bolsista da Fundação de Amparo e Pesquisa do Amazonas Fapeam e Fundação Centro de Análise, Pesquisa e Inovação Tecnológica - Fucapi.

** Professor titular da Escola Superior de Agricultura Luiz de Queiroz - Esalq/USP.
} 
municípios aos daqueles que os originaram. Embora seja a maneira mais prática, este método pode gerar testes estatísticos viesados, pois não considera as variações locacionais. Isso pode acarretar sinais invertidos dos parâmetros ou a subestimação e/ ou superestimação dos mesmos.

Até 2007, as análises do comportamento de variáveis censitárias eram restringidas às microrregiões ou macrorregiões brasileiras. Isso ocorria devido às mudanças territoriais resultantes dos desmembramentos dos municípios, que dificultavam as análises econômicas nesse nível de desagregação. Reunindo grande esforço para contornar essa deficiência, o Ipea/Nemesis ${ }^{1}$ recompôs todas as unidades territoriais do Brasil, desde 1872 até 2005 , que podem ser comparadas entre dois pontos no tempo (REIS et al., 2008). Contudo, não há séries de dados de AMC para o período de 1980 a 2000.

Apesar da grande contribuição do lpea/ Nemesis, as agregações utilizadas não contemplam algumas situações, entre as quais se destacam três:

- não são consideradas as proximidades geográficas de distritos a centros urbanos alocados em outras AMC. Consequentemente, um município pode fazer parte de uma AMC sem sofrer nenhuma influência dos municípios que the deram origem, mas sim dos municípios da AMC vizinha;

- a agregação de valores é feita pela simples soma dos dados, sem ponderações. Essa deficiência pode gerar viés nos testes estatísticos, visto que o método não permite variações locacionais; ${ }^{2}$

- a amostra fica reduzida, inferior ao número de municípios do períodobase.

$\mathrm{Na}$ literatura brasileira, existem algumas propostas no intuito de contornar os problemas das AMC. Paiva (2007 e 2008) aborda uma metodologia elaborada na Fundação de Economia e Estatística e Universidade de Santa Cruz do Sul. Segundo o autor, os valores absolutos, associados aos municípios criados num intervalo de tempo, são imputados aos municípios que lhes deram origem, na proporção da contribuição dos mesmos. Este método corrige a falha de proporção de agregação dos dados, porém, não elimina os efeitos que os municípios geradores causam nos novos municípios, isto é, o problema da proximidade geográfica.

Para identificar e quantificar áreas urbanas, Feitosa et al. (2005) propõem metodologia para a compatibilização da geometria dos setores censitários e dos seus respectivos dados. De acordo com os autores, essa metodologia permite a agregação e desagregação de alguns setores devido à integração de dados populacionais a dados do meio físico. Contudo, o processo parece tornar-se mais difícil à medida que se expande a área de análise, pois é preciso combinar imagens de satélites em dois períodos distintos. Portanto, este método tem mais aplicabilidade numa área pequena, como uma cidade, por exemplo, além de depender de imagens de satélite.

Outra proposta de compatibilização pode ser vista em Chein et al. (2004) apud Souza (2007). Os autores fazem a re-agregação de dados de três formas: grupos de municípios criados a partir daqueles existentes no ano-base; grupos cuja origem não é do ano-base, mas posterior; e grupos de municípios criados a partir de mais de uma localidade. O último grupo é re-agregado seguindo o modelo de polarização. O método tem a vantagem de manter os mesmos municípios do ano-base, mas a forma de re-agregação obedece aos recortes políticos. Isso limita a re-agregação de dados a um município polarizador que está em outro Estado, por exemplo.

Umbelino e Barbiere (2008) apresentam uma proposta de compatibilização no nível de setor censitário. Tal grau de detalhamento é muito útil na escala urbana, uma vez que facilita, sobremaneira, o planejamento de uma cidade. Para análises que envolvem os

\footnotetext{
1 Todas as séries construídas estão disponíveis em: <http;//www.ipeadata.gov.br>

2 Talvez por isso, muitas séries não são disponibilizadas pelo Ipea.
} 
municípios de um Estado ou do país, isso não é necessário, porém, são requeridas ponderações das variáveis censitárias.

Neste trabalho, propõe-se um método alternativo de análise com AMC, aplicando os Polígonos de Voronoi - PV e um método para agregar os dados por ponderação. Espera-se que esses métodos atenuem os problemas citados, já que levam em conta a distância geográfica, distribuem as variáveis com ponderações e mantêm a amostra do ano-base. A utilização de PV tem a vantagem de determinar as AMC com base nas áreas de influência que cada município gerador tem sobre os novos municípios, sem a limitação das divisões políticas. Para isso, faz-se uso de Sistema de Informações Georreferenciadas - SIG, amplamente difundido em diversas áreas do conhecimento. Num SIG, todas as informações são armazenadas num banco de dados e alocadas em pontos de um mapa, que pode ser um município, zona, região, entre outras formas (MONMONIER, 1997).

Uma vez construídas as AMC por meio de PV, ponderam-se os dados das variáveis censitárias nessas AMC. Essa abordagem permite reduzir os vieses dos testes estatísticos. A variável salário, por exemplo, se apenas somada como no método AMC/ Ipea, gera valores muito elevados para as AMC com maior número de agregações. Por outro lado, os municípios que não foram desmembrados continuam com seus valores originais e as AMC de menor agregação ficam com valores intermediários. Neste caso, o peso da variável salário seria expressivamente alterado entre as localidades e a média das observações seria superestimada. Ou seja, a variação dos salários em uma localidade é muito superior à de outra localidade, quando poderia ser a mesma. Essas disparidades geram parâmetros viesados, que podem ter seus valores subestimados, superestimados ou sinais invertidos.

No intuito de testar os métodos propostos, busca-se avaliar as mudanças populacionais ocorridas na Região Norte, entre 1980 e 2000, à luz da Nova Geografia Econômica - NGE, comparando-os com o método de AMC por divisão territorial, adotado pelo Instituto de Pesquisa Econômica Aplicada - Ipea. A Região Norte é a maior do país, onde as diferenças geográficas e socioeconômicas são bastante acentuadas em relação ao resto do Brasil. Adicionalmente, segundo Reis et al. (2008), é nesta região que ocorreu o maior número de desmembramentos territoriais.

Para atingir os objetivos desse trabalho, faz-se necessário construir as AMC para compatibilizar os censos de 1980 e 2000. Desse modo, adotam-se o método das AMC do Ipea (AMC/Ipea) e o método aqui proposto, os Polígonos de Voronoi (AMC/ PV). No intuito de validar a proposta deste artigo, comparam-se esses dois métodos, aplicando-os à Região Norte do Brasil. Para isso, utilizam-se variáveis censitárias que, de acordo com a NGE, influenciam nas aglomerações populacionais. O teste será feito via método econométrico de Mínimos Quadrados Ordinários. Espera-se obter resultados mais confiáveis a respeito do comportamento das variáveis socioeconômicas.

Em síntese, este artigo está estruturado da seguinte forma: além dessa introdução, na seção a seguir são apresentados os antecedentes do crescimento populacional na Região Norte e a definição das AMC e dos polígonos de Voronoi; na seção seguinte é descrita a metodologia, na qual são demonstrados os procedimentos para redistribuir os dados censitários nas AMC, bem como o método econométrico para avaliar o crescimento populacional; posteriormente, são discutidos os resultados e, na última seção, apresentam-se as conclusões.

\section{Fundamentação}

A Região Norte, composta por sete Estados (Acre, Amapá, Amazonas, Pará, Rondônia, Roraima e Tocantins), é a maior do Brasil em extensão, com uma área de 3,9 milhões de quilômetros quadrados, que representam cerca de $42,3 \%$ do território brasileiro, e registra uma das maiores taxas de crescimento populacional do país nas últimas décadas. Em 1985, por exemplo, sua população respondia por $6,21 \%$ da população brasileira, aumentando para 8,04\%, em 2006, com um incremento de $29,6 \%$. Seu processo de urbanização é igualmente diferenciado, com elevada concentração em 
algumas capitais. Manaus, por exemplo, detém $51 \%$ da população do Estado; Macapá, 59,8\%; Boa Vista, 62\%; Rio Branco, 46\% (CONSIDERA; MEDINA, 1998; SILVA; MEDINA, 1999; IBGE, 2008; SILVA, 2009).

Esse crescimento, além de não ser homogêneo, está associado à maturação dos investimentos públicos e aos incentivos fiscais concedidos nas décadas de 1960 e 1970. Isso impulsionou o aumento populacional a partir de fins dos anos 1970 e por toda a década 1980. Contudo, a imigração acelerada nesse período teve redução substancial nos anos 1990 e 2000 , pouco contribuindo para o aumento recente da população, que se deve, basicamente, ao crescimento vegetativo. Por outro lado, a migração intrarregional teve incremento expressivo, decorrente da exaustão de recursos naturais, concentração fundiária, processo de mecanização nas zonas rurais, aumento das áreas dedicadas à pecuária e expansão da fronteira agrícola e mineral (BRASIL, 1997; OLIVEIRA; SIMÕES, 2004). Tal processo ocasionou aumento da população das cidades, com forte migração das zonas rurais para urbanas (GOLGHER; MARQUES, 2006). Conforme preconiza a NGE, esse fluxo migratório às cidades está ligado à procura por qualidade de vida, amenidades urbanas, renda e acessibilidade a bens e serviços (FUJITA et al., 2002; GLAESER et al. 1995, 1998).

O cenário descrito desperta interesse em analisar o crescimento populacional da Região Norte no nível municipal. No entanto, existem alguns fatores que dificultam essa análise, que estão diretamente ligados às mudanças territoriais na região, descritas na seção seguinte.

\section{As Áreas Mínimas Comparáveis - AMC}

Durante o período analisado, ocorreram expressivas modificações geográficas na Região Norte. Alguns municípios foram incorporados a outros, assim como foram criados novos. A maior parte dessas modificações deve-se à elevação de categoria de Território para Estado, como Rondônia, em 1982, Amapá e Roraima, em 1991, e o desmembramento do Estado de Goiás para gerar o Tocantins, em 1989. O mesmo processo ocorreu com a criação de novos municípios, desmembrados daqueles existentes em 1980. Essas mudanças ocasionaram problemas de comparações intercensitárias (REIS et al., 2008).

Sob esse aspecto, analisar o comportamento de uma variável de um município que foi desmembrado para gerar outros é uma tarefa complexa. Por isso, a solução usualmente encontrada se dá por meio de $\mathrm{AMC}$, as quais apresentam algumas falhas que causam vieses nos testes estatísticos. Análises de variações devem ser feitas tomando o período inicial como base e repetindo essa base nos períodos seguintes.

No caso da Região Norte, em 1980 havia 205 municípios e, com as mudanças territoriais, esse número aumentou para 449, em 2000 (IBGE, 1982, 2002). Por conseguinte, para que as variações sejam consistentes, deve-se considerar o ano 2000 com mesmo número de municípios de 1980. Esse é um grande problema ao se utilizar o método AMC/Ipea. Para obter as AMC, os dados são somados de acordo com a divisão territorial. Contudo, isso reduz a amostra. Por AMC/PV, a agregação é feita, mas preservando a base.

Os dados de AMC utilizados no Brasil, oferecidos pelo Ipea, abrangem de 1872 até 2000 (REIS et al., 2008). Grande parte dos trabalhos aplicados, que lidam com o problema das AMC, utiliza essas séries de tempo. Ocorre que a metodologia adotada para compor as AMC não permite produzir resultados plenamente satisfatórios em análises de dados espaciais. De fato, o agrupamento leva em consideração a divisão territorial dos municípios ${ }^{3}$ e não a proximidade entre as cidades. Para análise de dados que envolvem a influência do espaço

\footnotetext{
${ }^{3}$ Do ponto de vista legal, não há outra maneira de fazer a agregação senão da forma como a realizada pelo Ipea (REIS, et al., 2008).
} 
geográfico, é preciso considerar a divisão territorial, a proximidade geográfica e manter a amostra do ano-base, do contrário as taxas de variações dos dados ficam distorcidas.

Esse problema pode ocorrer quando dois ou mais municípios, cujas cidades-sede estão relativamente distantes uma da outra, são agrupados numa mesma AMC. Tal como mostra a Figura 1, os municípios $m_{1}$, $m_{2}$ e $m_{3}$ possuem pequenas aglomerações populacionais em zonas rurais e distritos, identificadas pelos círculos. Os municípios $m_{1}$ e $m_{2}$ foram desmembrados para gerar o município $n_{1}$ e o município $m_{3}$ foi desmembrado para gerar os municípios $n_{2}$ e $n_{3}$. Então, $m_{1}, m_{2}$ e $n_{1}$ mais suas respectivas zonas rurais e distritos compõem a $\mathrm{AMC}_{1}$, enquanto $m_{3}, n_{2}$ e $n_{3}$ mais suas zonas rurais e distritos formam a $\mathrm{AMC}_{2}$.

Conforme mostra a primeira ilustração, duas zonas rurais do município $m_{1}$ (círculos escuros) estão mais próximas da sede do município $m_{3}$ do que da sua própria sede. $\mathrm{O}$ mesmo pode ser observado para o município $m_{2}$, que tem uma de suas zonas rurais mais próxima da sede de $m_{1}$. Na ilustração, as duas zonas rurais do município $m_{1}$ sofrem mais influência da sede de $m_{3}$, sendo que ambas as sedes estão em AMC diferentes. Logo, havendo migração da zona rural de $m_{1}$ para $m_{3}$, esta não seria captada pelo método de cálculo da AMC usual. Isso distorce, inclusive, a taxa de variação das variáveis censitárias, pois a $\mathrm{AMC}_{1}$ poderia apresentar elevadas variações negativas e a $\mathrm{AMC}_{2}$, elevadas variações positivas.

Os $\mathrm{PV}$ resolvem o problema da proximidade, visto que permitem identificar as áreas de atração dos municípios $m_{1}, m_{2}$ e $m_{3}$. Essa área de atração pode também ser chamada de AMC, uma vez que agrupa os novos municípios em áreas comuns, de acordo com a proximidade com seu município gerador. Todo esse processo é feito, automaticamente, pelo SIG. Complementarmente, este método é o mais indicado para mapear valores

FIGURA 1

Áreas municipais de origem e Áreas Mínimas Comparáveis

Áreas de origem

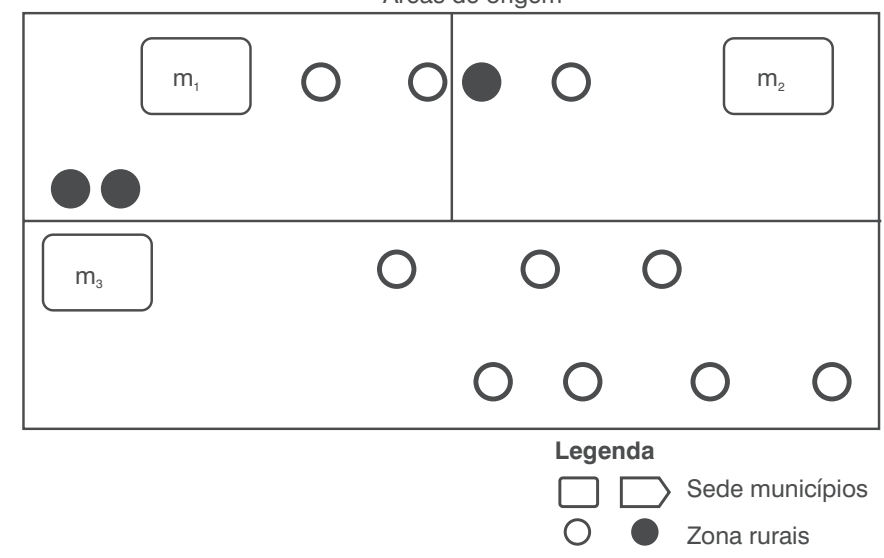

Áreas Mínimas Comparáveis

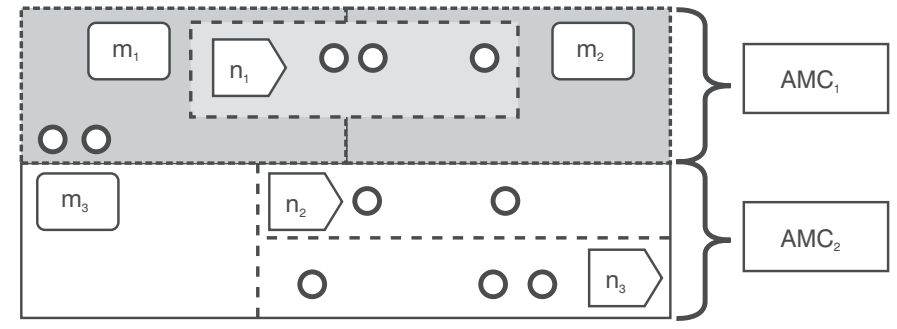

Fonte: Elaboração dos autores. 
de variáveis como população e produto, por exemplo, as quais não variam suavemente (LLOYD, 2007).

\section{O Polígono de Voronoi - PV}

Dado um conjunto de pontos no plano euclidiano, existe um conjunto associado de regiões em torno desses pontos. Assim, todos os locais dentro de determinada região estão mais próximos de um dos pontos do que de qualquer outro ponto. Estas regiões podem ser consideradas o dual do conjunto de pontos e são conhecidas como polígonos de proximidade, polígonos de Voronoi, regiões de Thiessen ou Dirichlet Cell (DIRICHLET, 1850; VORONOI, 1909; THIESSEN, 1912 apud KOLAHDOUZAN; SHAHABI, 2004).

O conjunto de localizações designado para cada ponto gerador ${ }^{4}$ forma uma região chamada de PV do ponto gerador $p$. O conjunto de PV associado a todos os geradores é chamado de diagrama de Voronoi (Figura 2). São coletivamente exaustivos, pois cada localização está associada com pelo menos um ponto gerador. São mutuamente excludentes, isto é, não têm intersecção, exceto para os seus limites. ${ }^{5}$ Os limites dos PV, chamados de arestas de Voronoi, são o conjunto de locais que podem ser atribuídos a mais de um gerador. A distância entre os pontos geralmente é calculada em linha reta, no espaço euclidiano. Dessa forma, o PV associado ao ponto gerador pi é dado pelo conjunto chamado de Diagrama de Voronoi gerado por $\mathrm{P}$, como ilustra a Figura 2.

Esses diagramas possuem algumas propriedades que representam a base para o modelo utilizado nesse trabalho:

- o diagrama de Voronoi de um conjunto de pontos $P$ é único;

- dois pontos $p_{i}$ e $p_{j}$ são vizinhos caso dividam uma mesma aresta; 6

- seja $n$ o número de pontos geradores e ne o número de arestas de Voronoi, então, ne $\leq 3 n-6$, isto é, o vértice é representado pela intersecção de três arestas que são equidistantes a três pontos geradores;

- considerando a propriedade anterior e o fato de que cada aresta de Voronoi é compartilhada exatamente

FIGURA 2

Diagrama de Voronoi

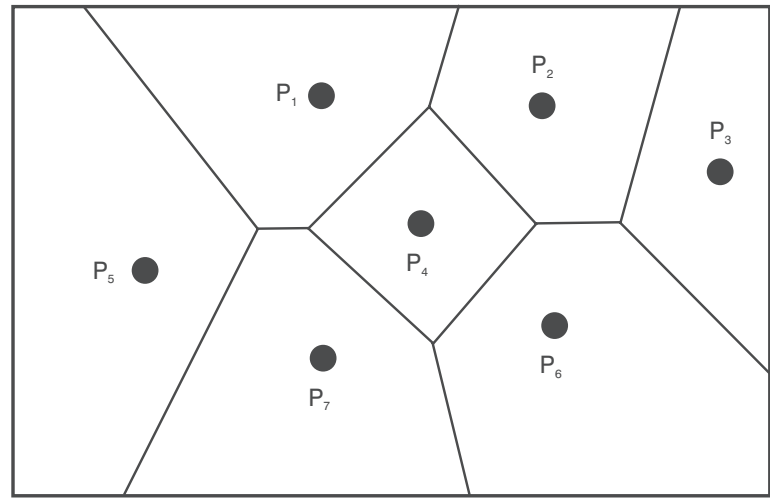

Fonte: Kolahdouzan e Shahabi (2004)

\footnotetext{
${ }^{4}$ Os pontos geradores são os municípios existentes em 1980. Desse modo, todos os pontos que forem adicionados (novos municípios) estarão próximos a algum dos pontos geradores.

${ }^{5}$ Caso uma cidade esteja na fronteira de um polígono, a distância que a separa de dois ou mais centros é similar. Quando isso ocorre, esta cidade pode sofrer influência de ambos os centros urbanos.

6 Uma aresta é a bissetriz perpendicular do segmento $p_{i} p_{j}$, ou seja, a quina de uma célula entre dois pontos geradores no diagrama.
} 
por dois PV (propriedade 2), nota-se que o número médio de arestas por polígono é de aproximadamente 6 , isto é, $2(3 n-6) / n=6-12 / n \leq 6$, a qual significa que, na média, cada gerador possui seis geradores adjacentes. ${ }^{7}$

Essa última propriedade é utilizada para derivar o algoritmo desse trabalho, que segue Kolahdouzan e Shahabi (2004) e Okabe et al. (1992).

Aplica-se um Diagrama de Voronoi em Redes, no qual a distância entre dois pontos no espaço é calculada pelo caminho ou pelo tempo mais curto de deslocamento, em vez da distância euclidiana. Por essa extensão do diagrama de Voronoi, a rede espacial pode ser modelada como grafos ponderados, 8 nos quais as intersecções são representadas pelos nodos do grafo e as rodovias e hidrovias são representadas pelas ligações entre os nodos. Os pesos podem ser a distância entre os nodos ou o tempo de viagem entre eles.

Na Figura $3, P_{1}, P_{2}$ e $P_{3}$ são os pontos geradores, que representam as cidades existentes em 1980. Os demais pontos correspondem aos municípios criados a partir de 1980, ligados por uma rede de rodovias ou hidrovias que estão conectadas umas às outras. Cada estilo de linha no diagrama corresponde a um conjunto de links de Voronoi de um gerador. Alguns links estão completamente contidos na área de um gerador, divididos pela linha mais espessa. $\mathrm{O}$ link conectando $\mathrm{P}_{6}$ e $\mathrm{P}_{9}$, por exemplo, está totalmente dentro da área ${ }^{9}$ de $\mathrm{P}_{1}$, enquanto outros estão parcialmente contidos em diferentes áreas, como é o caso do link que conecta $\mathrm{P}_{4}$ e $\mathrm{P}_{5}$, por exemplo, que está dividido entre as áreas de $\mathrm{P}_{1} \mathrm{e}$ $P_{2}$. Esse esquema representa a forma com que será desenvolvida a estrutura dos $\mathrm{PV}$ desse artigo.

\section{Fonte de dados e metodologia}

Para a construção das AMC de 1980 a 2000 , foram utilizadas as genealogias municipais publicadas pelo IBGE e outras fontes complementares, como leis estaduais e ajustamento da base territorial para comparação de dados dos censos, em

FIGURA 3

Diagrama de Voronoi em redes

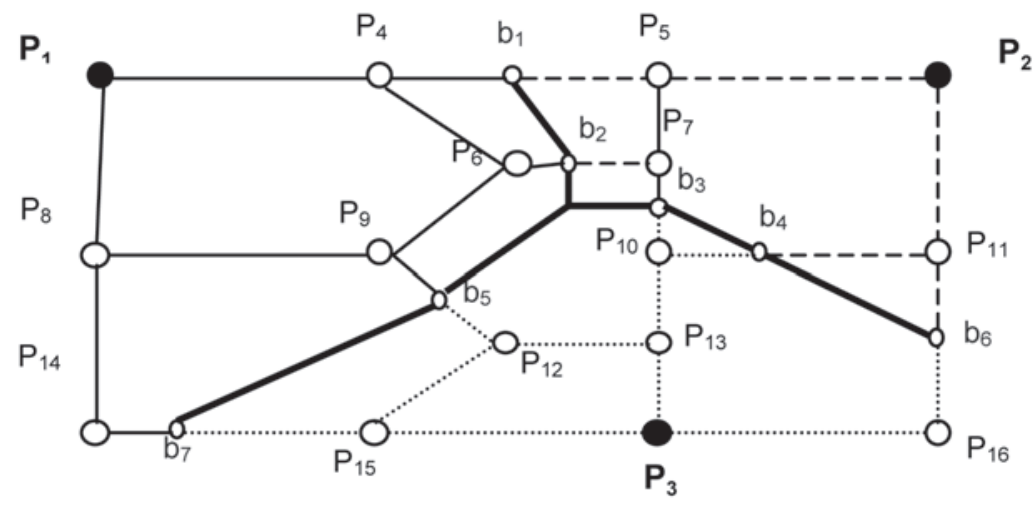

Fonte: Kolahdouzan e Shahabi (2004).

\footnotetext{
7 Note (Figura 3) que cada aresta é compartilhada por dois pontos geradores e, como há pelo menos seis pontos adjacentes a cada gerador, logo, $6 \times 2=12$.

8 Maiores detalhes em Okabe et al. (1992).

${ }^{9} \mathrm{~A}$ área do gerador $\mathrm{p}_{1}$ tem o segmento de $\mathrm{p}_{1}, \mathrm{~b}_{1}, \mathrm{~b}_{2}, \mathrm{~b}_{5} \mathrm{a} \mathrm{b}_{7}$. Já o $\mathrm{p}_{2}$ tem o segmento de $\mathrm{p}_{2}, \mathrm{~b}_{1}, \mathrm{~b}_{2}, \mathrm{~b}_{3}, \mathrm{~b}_{4}$ a $\mathrm{b}_{6}$.
} 
Bremaeker (2006). A base de dados foi construída a partir dos censos demográficos de 1980 e 2000. O recorte regional são todos os municípios da Região Norte. O mapa da divisão territorial e do sistema de transporte de 1980 foi digitalizado, tendo como base o mapa de $1982^{10}$ e 2006, disponibilizado pelo Departamento Nacional de Infraestrutura de Transporte - DNIT. As variáveis utilizadas para explicar o processo de aglomeração com base na NGE seguem a literatura, como em Partridge (2007), Andersen et al. (2002) e Souza (2008), e são detalhadas na seção do método econométrico.

A metodologia está dividida em três partes. Na primeira, são construídas as AMC no padrão do Ipea, seguindo Reis et al. (2008). Por AMC/PV, é colocado o mapa de 2000 sobre o de 1980. Dessa maneira, têm-se os municípios geradores e os gerados. O programa de georreferenciamento irá identificar as áreas de influência dos municípios de origem. Estas deverão abranger, ou não, certos municípios. O importante é que as AMC são criadas a partir da base, isto é, um processo do início para o fim, que mantém a amostra inicial. Em seguida, faz-se a agregação das variáveis censitárias utilizadas no método econométrico. $A$ agregação é feita por soma, no método AMC/Ipea e, por ponderação, no AMC/PV. $\mathrm{Na}$ última parte, com as AMC definidas e as variáveis devidamente alocadas, utiliza-se o método econométrico de MQO para avaliar o crescimento populacional, comparando os dois modelos de AMC.

\section{Ponderações dos dados nas AMC/lpea e $A M C / P V$}

Hipoteticamente, consideram-se os municípios $m_{1}$ e $m_{2}$ com população $p_{1}$ e $p_{2}$ em 1980. Estes municípios foram desmembrados e geraram quatro novos $\left(m_{3}, m_{4}, m_{5}\right.$ e $\left.m_{6}\right)$. Os municípios $m_{3}, . ., m_{6}$ foram criados com áreas tanto de $m_{1}$ quanto de $m_{2}$. Por essa lógica, para compor a AMC com os dados censitários de 2000 , por exemplo, a população desta área seria a soma da po- pulação de todos os municípios $p_{1}+\ldots . .+p_{6}$. Supondo-se que a participação da população de $m_{1}$ e $m_{2}$ em 1980 seja de $30 \%$ e $70 \%$, com o aumento do número de municípios em 2000, essa participação cai para 10\% e $40 \%$, respectivamente. Há então $50 \%$ de população que precisa ser redistribuída entre $m_{1}$ e $m_{2}$ de forma que seja possível calcular a variação populacional sobre a mesma base.

Conseqentemente, é necessário considerar a proporção da perda real de população dos municípios de origem. No exemplo anterior, $m_{1}$ perdeu $67 \%$ de sua população e $m_{2}, 43 \%$. Há também a migração dos habitantes das zonas rurais para urbanas, processo este que se intensificou nas últimas décadas (GOLGHER; MARQUES, 2006). Uma possível maneira de suavizar esses problemas é distribuir a população excedente com base na estrutura populacional das AMC em 2000, entre rural e urbana. Desse modo, a população excedente é distribuída levando em conta o dinamismo populacional no decorrer do período em análise. Para tanto, calcula-se a distribuição relativa da população rural e urbana do município $i$ no instante $t$, isto é, no ano 2000 . O sobrescrito $o$ identifica esse município como existente no ano-base, em 1980. Trata-se de um município que foi desmembrado - aqui chamado de município original - para gerar outros municípios. Assim:

$S R_{i t}^{o}=\frac{P R_{i t}^{o}}{P R_{i t}^{o}+P U_{i t}^{o}}$

em que $S R_{i t}^{o}$ é a participação relativa da população rural do município original $i$, no instante $t ; P R_{i t}^{o}$ é a população rural do município original $i$ e $P U_{i t}^{o}$ é a população urbana do município original $i$. O mesmo se aplica à população urbana:

$S U_{i t}^{o}=\frac{P U_{i t}^{o}}{P R_{i t}^{o}+P U_{i t}^{o}}$

em que $S U_{i t}^{o}$ é a participação relativa da população urbana do município original $i$.

Para redistribuir a população excedente, extrai-se a participação relativa do município original em relação à sua AMC na composição do ano $t$.

10 Gentilmente cedido pela pesquisadora Ana Maria Baruf/IPE/USP. 


$$
R A_{i t}^{o}=\frac{P R_{i t}^{o}}{\sum_{i=1}^{n} P R_{A t}^{o}}
$$

onde $R A_{i t}^{o}$ é a participação da população rural do município original $i$ em relação à população rural total da $A M C$, identificada pelo subscrito $\mathrm{A} ; P R_{A t}^{o}$ é a população rural original da AMC A. O mesmo se aplica à população urbana:

$U_{i t}^{o}=\frac{P U_{i t}^{o}}{\sum_{i=1}^{n} P U_{A t}^{o}}$

em que $U_{A t}^{o}$ é a participação da população urbana do município original i em relação à população urbana total da AMC $A$ em $t$. Com a participação relativa em relação à AMC A em (3) e (4), obtém-se a distribuição da população excedente rural e urbana, identificada pelo sobrescrito $E$, da seguinte forma:

$$
P R_{i t}^{d}=P R_{i t}^{o}+R A_{i t}^{o} \sum_{i=1}^{n} P R_{A t}^{E}
$$

em que $P R_{i t}^{d}$ é a população rural do município original $i$, adicionada da população rural excedente dos municípios criados entre 1980 e 2000. O sobrescrito $d$ identifica que essa é a população obtida a partir da soma da população original mais a excedente; $P R_{i t}^{o}$ é a população rural do município original $i ; R A_{i t}^{o}$ é a participação relativa da população rural desse município em relação à população da AMC A, obtida em (3); e $P R_{A t}^{E}$ é a população rural excedente $E$, da AMC $A$ dos municípios criados a partir de 1980. O mesmo se aplica à população urbana:

$$
P U_{i t}^{d}=P U_{i t}^{o}+U A_{i t}^{o} \sum_{i=1}^{n} P U_{A t}^{E}
$$

Por fim, a população dos municípios originais adicionada da população excedente conforme (5) e (6) deve ser distribuída na mesma estrutura de (1) e (2). Por meio desse método, a nova população distribuída fica mais próxima da realidade apresentada em 2000. Logo:

$$
\begin{aligned}
& P R_{i t}^{d o}=S R_{i t}^{o}\left(P U_{i t}^{d}+P R_{i t}^{d}\right) \\
& P U_{i t}^{d o}=S U_{i t}^{o}\left(P U_{i t}^{d}+P R_{i t}^{d}\right)
\end{aligned}
$$

onde $P R_{i t}^{d o}$ e $P U_{i t}^{d o}$ constituem a nova população rural e urbana dos municípios originais $i$ adicionados a partir da distribuição $d$ feita em (4) e (5). O sobrescrito do representa a nova distribuição populacional $d$ dos municípios originais $o$. Desse modo, é possível realizar a análise de variação populacional sobre a mesma base, agora que a população dos municípios criados entre 1980 e 2000 foram devidamente "devolvidas" (distribuídas) aos municípios que lhes deram origem. Esse método capta tanto a perda de população resultante do desmembramento, como o movimento migratório intermunicipal de zonas rurais e urbanas.

\section{Método econométrico}

A finalidade do modelo econométrico é comparar a performance dos ajustamentos das AMC/Ipea e AMC/PV. Por conseguinte, serão estimados quatro modelos: dois (rural e urbano) aplicados às AMC/Ipea e o mesmo para AMC/PV. A divisão dos modelos entre rural e urbano visa captar os efeitos de mudanças populacionais isoladamente. Isso facilita a interpretação dos dados à luz da NGE, cujo um de seus pressupostos versa sobre os processos de aglomerações populacionais. O modelo rural aplicado em ambos os métodos de AMC é o seguinte:

$$
\begin{aligned}
& \mathrm{POPr}_{i}=\alpha+\beta M I G_{i}+\gamma F E C_{i}+\delta I D H_{i}+\eta S A R_{i}+ \\
& +\theta I R T_{i}+\lambda O F E_{i}+\mu C O N_{i}+\rho M E C_{i}+\varepsilon
\end{aligned}
$$

em que $P O P r$ é a variação da população rural no município i; MIG (migração da zona rural para urbana); FEC (taxa de fecundidade); IDH (Índice de Desenvolvimento Humano); SAR (salários pagos nas zonas rurais); ITR (iteração do diferencial de salário com a área total de terras utilizadas); OFE (área total dedicada à agropecuária e pecuária); $\varepsilon$ (termo de erro) e as demais letras gregas representam os coeficientes a serem estimados.

O modelo urbano para AMC/Ipea e AMC/PV é o seguinte:

$$
\begin{aligned}
& P O P u_{i}=\alpha+\beta M I G_{i}+\gamma F E C_{i}+\delta I D H+\eta S A U_{i}+ \\
& +\beta D S L_{i}+\varepsilon
\end{aligned}
$$

onde $P O P u$ é a taxa de variação populacional na zona urbana, no município $i ; S A U$ (salários pagos nas zonas urbanas); DSL 
(proporção dos salários pagos nas zonas urbanas em relação à rural). ${ }^{11}$

Nesses modelos, a variável MIG é uma proxy que capta a mudança da população rural para urbana, gerando os processos aglomerativos preconizados pela NGE (FUJITA et al., 2002). Este processo foi intensificado a partir dos anos 1990, com o crescimento econômico das cidades; logo, espera-se sinal negativo no modelo rural e positivo no urbano, indicando que quanto mais atrativas forem as cidades, mais pessoas se deslocam da zona rural para urbana.

A variável OFE do modelo rural é uma proxy para captar o movimento migratório interestadual. Em fins da década de 1970 e na de 1980, a onda migratória para a Região Norte foi intensa, com decréscimo nos anos 1990. Parte dessa onda migratória foi ocasionada pelos incentivos do governo federal, por meio da reforma agrária, disponibilizando terras em todos os Estados daquela região. Apesar da expansão da área dedicada à pecuária, esperam-se coeficientes positivos para essa variável, indicando que, quanto maior for a oferta de terras na Região Norte, maior é o crescimento populacional rural.

Em contraste, a variável CON capta os efeitos de concentração da propriedade, ${ }^{12} \mathrm{O}$ qual reduz a oferta de emprego, estimulando o movimento rural-urbano. Complementarmente, a variável ITR (iteração da oferta de terras com o diferencial de salários) deverá captar as vantagens ou desvantagens da migração rural-urbana.

A variável $F E C$ será usada como proxy para o crescimento vegetativo, ${ }^{13}$ da qual se espera sinal positivo. $\mathrm{O} I D H$ reflete as condições de vida da população urbana, no nível de renda, educação e saúde. Espera-se sinal negativo no modelo rural e positivo no urbano. (MARTINS; ALMEIDA, 2000; MOREIRA, 2000). As variáveis SAR e SAU servirão como proxies para captar a força de atração da renda em ambas as zonas. O sinal esperado é positivo, indicando que, quanto maior for o salário, maior é o poder de atração de trabalhadores, contribuindo para a aglomeração (ELLISON; GLAESER, 1999). No modelo rural, a variável MEC (mecanização) ${ }^{14}$ contrasta com os salários, isto é, por mais que os salários sejam atrativos nas zonas rurais, o processo de mecanização impede que a oferta de trabalho seja expandida; logo, espera-se sinal negativo dessa variável.

O modelo econométrico será estimado por MQO, com todas as variáveis expressas em taxas logarítmicas. O período de variação é de 1980 a 2000, com taxas calculadas da seguinte forma: $\ln (\mathrm{x})_{2000}-\ln (\mathrm{x})_{1980}$. Isso evita correlações espúrias, além de o período de tempo relativamente longo evitar, também, problemas de endogeneidade (BAUM, 2006). Por serem dados cross-section, é provável que a hipótese de homocedasticidade seja violada, a qual gera estimadores de MQO viesados e não eficientes (GREENE, 2002). Para evitar essa falha, o modelo será estimado na versão robusta, significando que, nessa abordagem, não se impõe nenhuma restrição ao comportamento dos erros do modelo (BAUM, 2006).

\section{Resultados}

Na Região Norte havia, em 1980, 205 municípios, número que passou para 449 , em 2000. Os 244 novos municípios foram originados a partir tanto de um único município, como de mais de um. Pelo método AMC/lpea, os novos municípios são re-agregados àqueles de origem, formando as AMC.

Como exemplo dos resultados, ${ }^{15}$ mostra-se o caso de Nova Rosalândia (último diagrama da coluna do meio, da Figura 4),

\footnotetext{
${ }^{11}$ Foram feitos testes com o diferencial de salários no modelo rural, contudo, o melhor ajuste se deu tal como representado acima.

12 Proxy obtida com base no número de estabelecimentos agrícolas.

13 É mensurada pelo número médio de filhos nascidos vivos, por mulher, ao final do seu período reprodutivo, pressupondo ausência de mortalidade na coorte (IDB, 2009).

14 Proxy obtida com base no número de tratores utilizados.

15 Este é apenas um exemplo de como foi feita a agregação. Demonstrá-la integralmente, além de exaustivo, requer muito espaço.
} 
no Estado do Tocantins. Este município foi emancipado em 1988, desmembrado dos municípios de Cristalândia, Porto Nacional e Fátima. O município de Fátima foi emancipado em 1982, a partir do município de Porto Nacional, que, por sua vez, também deu origem aos municípios de Ipueiras, Silvanópolis e Palmas.

Seguindo a lógica da divisão territorial para criar as AMC, a área de Nova Rosalândia é somada à área de Fátima, Cristalândia e Porto Nacional. Entretanto, Cristalândia gerou Aliança do Tocantins, que gerou Crixás do Tocantins. O município de Aliança do Tocantins foi também gerado com áreas de Brejinho de Nazaré e Gurupi. Brejinho de Nazaré gerou Santa Rita do Tocantins e Gurupi e este, por sua vez, gerou Cariri do Tocantins, o qual foi também gerado por Dueré. Porto Nacional também gerou outros três municípios, além de Fátima e Nova Rosalândia. Nessa rede de municípios, todas as áreas são somadas, formando uma grande AMC, como demonstrado na Figura 4. Esse processo se repete para todas as AMC. As variáveis socioeconômicas são alocadas nessas AMC, obedecendo ao mesmo processo de soma, pelo método AMC/Ipea.

Apesar da simplicidade dessa forma de agregação, a análise das variáveis socioeconômicas perde poder explicativo, porque, primeiro, o número da amostra fica reduzido

FIGURA 4

Formação de Área Mínima Comparável

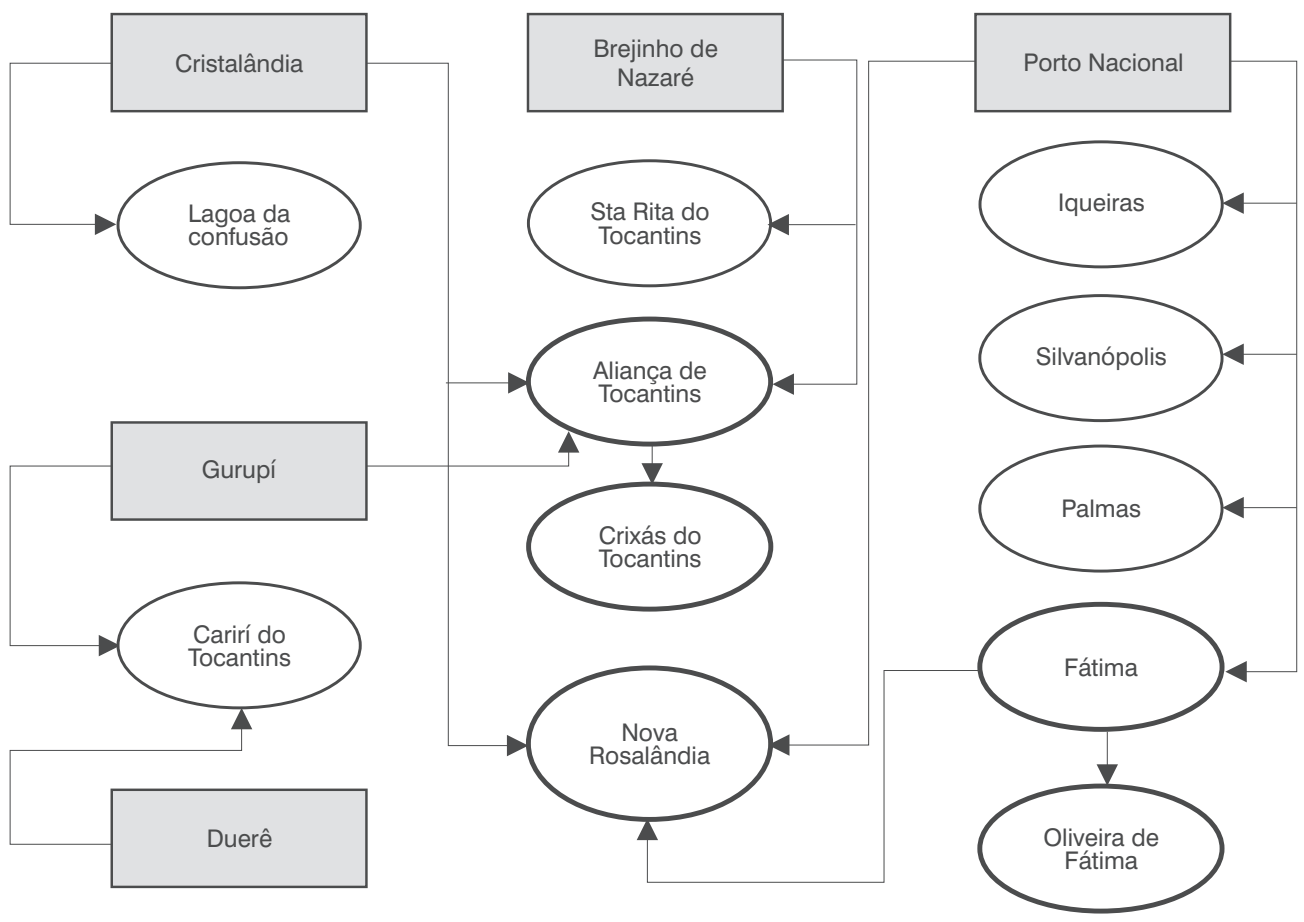

Municípios geradores (existentes em 1980)

Municípios gerados a partir de 1980

Municípios gerados e, posteriormente, geradores

Fonte: Elaboração dos autores. 
e, segundo, os centroides dos municípios em 1980 estão relativamente distantes um do outro. Aliança do Tocantins, por exemplo, faz parte da AMC da Figura 4, desmembrado do município de Brejinho de Nazaré a 63 $\mathrm{km}$ de distância, Cristalândia, a $116 \mathrm{~km}$ e Gurupi, a 50 km. Observando os PV na Figura 5, nota-se que o município de Aliança do Tocantins está no mesmo polígono de Dueré. Isso ocorre porque eles estão separados por apenas $49 \mathrm{~km}$ de distância. $\mathrm{Da}$ mesma forma, Ipueiras, que embora tenha sido desmembrado de Porto Nacional, está muito mais próximo de Brejinho de Nazaré. Consequentemente, por questão de proximidade, é mais provável que o município de Aliança do Tocantins sofra mais influência de Dueré e Gurupi, assim como Ipueiras sofra mais influência de Brejinho de Nazaré, conforme demonstrado no Diagrama de Voronoi (Figura 5).

Com efeito, um grande centro urbano pode ter mais influência sobre uma cidade que está a $200 \mathrm{~km}$ distância do que sobre outra a apenas $50 \mathrm{~km}$, por exemplo. Obviamente, o município mais próximo deveria

FIGURA 5

Diagrama de Voronoi no Estado do Tocantins

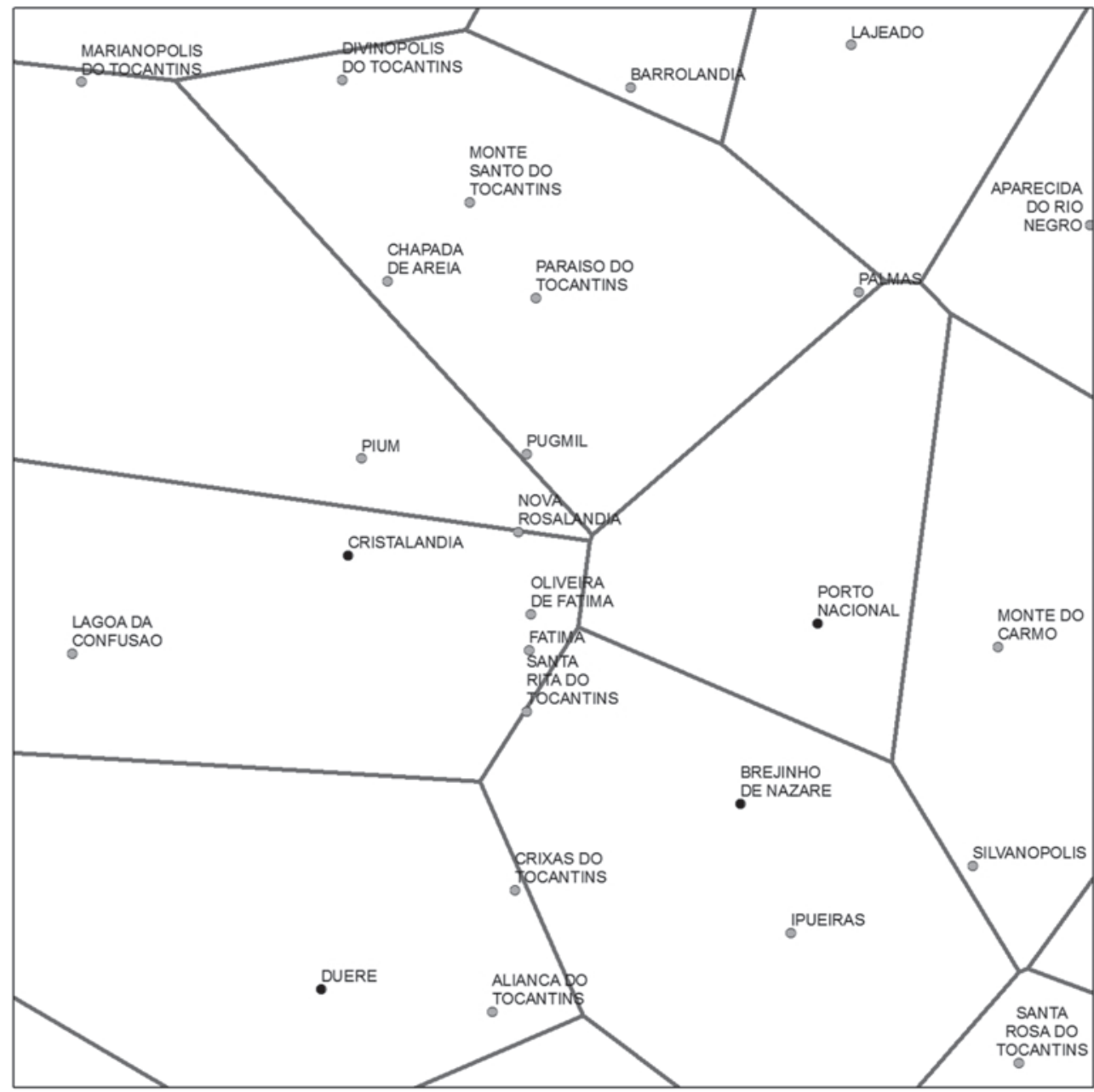

Fonte: Elaboração dos autores com base no software ArcGis 9.3. 
sofrer maior influência do centro urbano e não o contrário. Os PV contornam os problemas citados.

Por meio desse método, todos os municípios de origem são preservados, neste caso, 205. O mesmo não acontece com o AMC/Ipea, cuja amostra será sempre inferior, ${ }^{16}$ reduzindo, inclusive, o poder explicativo dos regressores. Os 244 novos municípios são re-agregados àqueles de origem, de acordo com sua proximidade nos PV, como demonstrado nas Figuras 5 e 6 . As variáveis socioeconômicas, por sua vez, são realocadas seguindo o método da ponderação.

A agregação por AMC/Ipea, conforme representada pela Figura 4, totalizou 79 AMC para a Região Norte. Na forma de polígono, como da Figura 5, o total é de 91. Seguindo o método de agregação AMC/Ipea, o Estado do Acre tem seis $A M C,{ }^{17}$ nas quais estão agregados 19 municípios, enquanto três municípios não sofreram nenhuma alteração territorial. Logo, há uma amostra de nove localidades. Pela aglomeração feita por PV, foram construídas nove AMC que agrupam 20 municípios, totalizando uma amostra de 12 localidades (3+9). Uma diferença fundamental entre os modelos é que por AMC/ Ipea, há a limitação territorial e, por AMC/PV, vale a proximidade. Dessa maneira, a AMC de um Estado pode agregar um município de outro Estado. Isso é fundamental, porque os indivíduos migram para onde o custo-benefício é mais vantajoso. O município de Guajará, por exemplo, localizado no extremo sudoeste do Amazonas, está muito mais próximo de Cruzeiro do Sul, no Acre, do que de seu município "mãe". Por isso, foi incorporado na AMC de Cruzeiro do Sul, ${ }^{18}$ sendo esta a cidade atrativa de migração.

FIGURA 6

Diagrama de Voronoi para a Região Norte

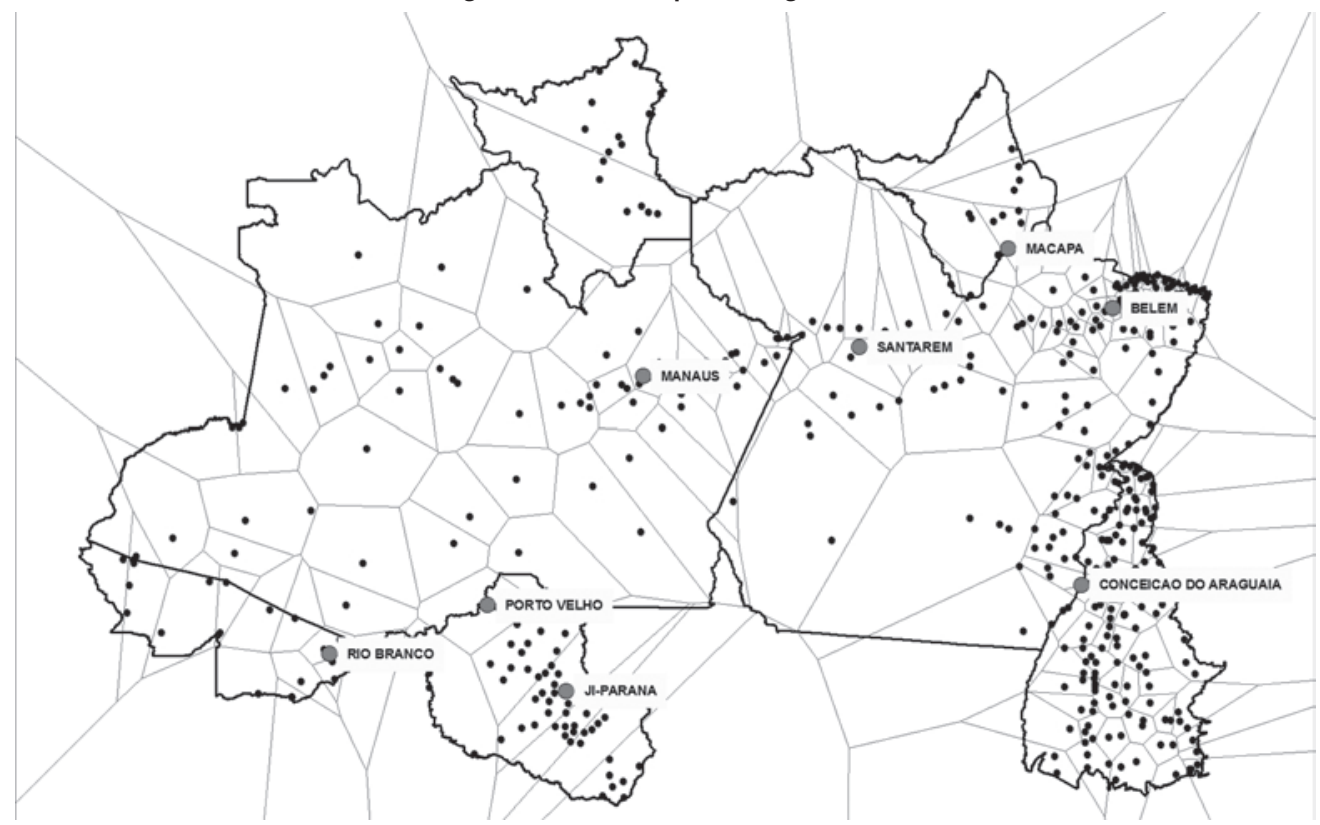

Fonte: Elaboração dos autores com base no software ArcGis 9.3.

\footnotetext{
${ }^{16}$ Quando um Estado tem poucos municípios, como Amapá e Roraima, as amostras podem ter o mesmo tamanho, mas o AMC/PV nunca será inferior, porque preserva a amostra do ano-base.

17 Cada AMC representa uma localidade e, dentro desta localidade, estão agrupados dois ou mais municípios. O que compõe a amostra do modelo são as $\mathrm{AMC}+$ os municípios que não fazem parte de nenhuma AMC, ou seja, aqueles que não foram desmembrados, ou que não estão em proximidade com nenhum outro.

${ }^{18}$ A diferença é expressiva. Guajará-AM foi desmembrado de Ipixuna-AM e suas sedes estão separadas por 11 horas de viagem. No entanto, Guajará fica a apenas uma hora de Cruzeiro do Sul-AC.
} 
No Amazonas, foram construídas dez AMC por AMC/lpea, aglomerando 38 municípios. Na amostra, 24 municípios não foram desmembrados, totalizando 34 localidades $(10+24)$. Por AMC/PV, foram construídas 13 AMC que agregam 29 municípios, mais 31 municípios que não foram incorporados a nenhuma AMC, somando 44 localidades. ${ }^{19}$ No Amazonas e Pará, as áreas dos municípios são muito extensas e, por essa razão, muitos não foram incorporados a nenhuma AMC, seguindo o método $\mathrm{AMC} / \mathrm{PV}$. Essa distância implica que não havia nenhuma cidade próxima o suficiente que pudesse influenciar, ou sofrer qualquer influência desses municípios. Nos Estados do Amapá e Roraima, não houve diferença de aglomerações entre os métodos empregados.

O Estado do Pará apresentou 25 AMC por AMC/Ipea, que agrupam 92 municípios, enquanto 51 não foram desmembrados, totalizando 76 localidades $(25+51)$. Por AMC/PV, foram construídas 24 AMC que agrupam 80 municípios, enquanto 59 não foram alterados, totalizando 83 localidades (24+59). Tal como ocorreu no Amazonas, alguns municípios do Pará foram mantidos isolados por não influenciarem os novos municípios, devido às longas distâncias que os separam. Ainda, o município de Santa Maria das Barreiras foi incorporado à $A M C$ do município de Araguacema-TO; Brejo Grande do Araguaia e Palestina do Pará foram incluídos na AMC de Araguatins-TO; Piçarra e São Geraldo do Araguaia, na AMC de Xambioá-TO. Então, incorporaram-se quatro municípios às $A M C$ do Tocantins e um à $A M C$ do Amazonas.

No Tocantins foram construídas 35 AMC pelo método AMC/Ipea, com 129 municípios agregados. Somam-se a esse resultado dez municípios que não sofreram divisões territoriais, totalizando amostra de 45 localidades $(35+10)$. Por AMC/PV, foram construídas 45 AMC que agregam 137 municípios, enquanto sete foram mantidos inalterados, totalizando 52 localidades $(45+7)$.

\section{Comparação de desempenho dos modelos}

Na Tabela 1 estão descritos os resultados da estimação obtidos no modelo para zona rural, no qual a variável resposta é o logaritmo da variação da população nas zonas rurais. O conjunto de dados contém as variáveis que se espera influenciar nas variações populacionais, negativa e positivamente. A primeira coluna mostra que o modelo rural com AMC/Ipea não foi tão bem ajustado quanto aquele com AMC/PV. As variáveis utilizadas explicam $58,4 \%$ das variações na aglomeração populacional, contra $77 \%$ no modelo de AMC/PV. A variável fecundidade foi a única que não mostrou evidência de poder explicativo nos dois modelos, talvez pela sua própria redução ao longo do tempo, pela importância crescente de outras variáveis, como salários e IDH, e pela migração para zonas urbanas.

Como salientado, o modelo por AMC/ Ipea pode gerar alguns vieses e os resultados da regressão demonstram isso. $O$ coeficiente da variável IDH parece estar superestimado, com elevada elasticidade; a iteração entre oferta de terra e diferencial de salário, que deveria ser negativa, no entanto é positiva. O mesmo se aplica ao coeficiente da variável concentração de terras. No modelo $\mathrm{AMC/PV}$, a regressão não só foi mais bem ajustada, como também apresentou os sinais de acordo com a teoria. A variável de maior impacto na redução da população rural, de acordo com o modelo AMC/PV, é o IDH. Isso significa que as pessoas das zonas rurais estão migrando em busca de melhor qualidade de vida, supostamente alcançada nas zonas urbanas.

Embora o impacto dos salários pagos nas zonas rurais seja ainda expressivo em aumentar a população rural, há forças contrárias atuando. Apesar de a oferta de terra ainda ter efeitos positivos, o baixo coeficiente dessa variável dá sinais de enfraquecimento da demanda por trabalho nas zonas rurais (para cada aumento de $1 \%$ na

\footnotetext{
$19 \mathrm{O}$ município de Nhamundá/AM foi incorporado à AMC do município de Faro/PA.
} 
oferta de terras, a população rural aumenta apenas $0,08 \%$ ). Esse enfraquecimento pode ser resultado da concentração de propriedade, utilização das terras para pastagens e inserção de empresas capitalistas que mecanizaram a produção no campo, exigindo cada vez menos mão de obra. De fato, os coeficientes negativos dessas variáveis confirmam essa assertiva no modelo $\mathrm{AMC} / \mathrm{PV}$, que estão plenamente de acordo com os resultados observados nos censos agropecuários. Apesar disso, os resultados do modelo $\mathrm{AMC} / \mathrm{Ipea}$ indicam o contrário, deixando claro o viés dos resultados.

De acordo com o exposto, evidenciou-se que o modelo AMC/PV explica melhor as variações populacionais nas zonas rurais, tanto pela sua qualidade de ajustamento quanto pelos coeficientes das variáveis explanatórias.

Para explicar as aglomerações nas zonas urbanas, utilizou-se como variável dependente o logaritmo da variação populacional nas zonas urbanas. A partir da teoria, espera-se que todas as variáveis explanatórias utilizadas influenciem, positivamente, o crescimento populacional nas zonas urbanas. $\mathrm{Na}$ Tabela 2, estão descritos os resultados da estimação obtidos no modelo para zona urbana, no qual a variável resposta é o logaritmo da variação da população nas zonas urbanas. Todos os coeficientes apresentam os sinais esperados no modelo AMC/PV, enquanto no modelo $\mathrm{AMC/Ipea} \mathrm{há} \mathrm{três} \mathrm{variáveis} \mathrm{com}$ coeficientes negativos. Além disso, nota-se que o grau de ajustamento do modelo AMC/ Ipea é bastante inferior ao do AMC/PV. Este explica apenas $35 \%$ das mudanças nas aglomerações urbanas. No modelo AMC/ Ipea, o grau de ajustamento é de $79,2 \%$.

O crescimento da população urbana está estreitamente relacionado com os fatores de redução da população rural. A variável proxy para a migração capta esse efeito. Para cada aumento de $1 \%$ na migração rural, a população urbana aumenta $0,26 \%$. Entretanto, no modelo AMC/Ipea esse efeito é contrário. O mesmo ocorre com as variáveis diferencial de salários e $\mathrm{IDH}$, que deveriam ser positivas, mas, ao contrário, são negativas. No modelo AMC/ PV, para cada aumento de $1 \%$ no diferencial de salário da zona urbana para zona rural, a população urbana aumenta $0,46 \%$. Vale destacar que, no modelo rural, a variável diferencial de salário produziu melhor efeito quando realizada sua iteração com a oferta de terra. Daí a razão de não constar essa variável isolada no modelo rural, já que reduziria a parcimônia do modelo. Apesar do bom ajustamento do modelo AMC/PV, a variável

TABELA 1

Resultados da regressão para o modelo rural

\begin{tabular}{|c|c|c|}
\hline \multirow{2}{*}{ Variáveis } & \multicolumn{2}{|c|}{ Coeficientes } \\
\hline & AMC/Ipea & AMC/PV \\
\hline Migração rural-urbana & $-0.245^{\star \star \star}$ & $-0.142^{\star \star \star}$ \\
\hline Fecundidade & 0.263 & 0.055 \\
\hline IDH & 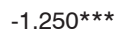 & $-0.735^{\star \star \star}$ \\
\hline Salário zona rural & $0.333^{\star * *}$ & $0.603^{* * *}$ \\
\hline Oferta de terra & 0.002 & $0.087^{\star \star \star}$ \\
\hline Iteração (terra e dif. salário) & $0.067^{\star}$ & $-0.021 *$ \\
\hline Concentração de terras & 0.010 & $-0.066^{\star \star}$ \\
\hline Mecanização & -0.017 & $-0.111 * \star \star$ \\
\hline Constante & $0.704^{\star * *}$ & $0.500 * * *$ \\
\hline $\mathrm{R}^{2}$ & 0.584 & 0.770 \\
\hline $\mathrm{F}$ & 27.9 & 81.9 \\
\hline $\mathrm{N}$ & 168 & 204 \\
\hline
\end{tabular}

Fonte: Elaboração dos autores.

Nota: ${ }^{* \star}$ significativo a $1 \%$ de probabilidade; ${ }^{* *}$ a $5 \%$; * a $10 \%$. Estimativas robustas. 
TABELA 2

Resultados da regressão para o modelo urbano

\begin{tabular}{|c|c|c|}
\hline \multirow{2}{*}{ Variáveis } & \multicolumn{2}{|c|}{ Coeficientes } \\
\hline & AMC/Ipea & AMC/PV \\
\hline Migração rural-urbana & -0.010 & $0.261^{* \star *}$ \\
\hline Fecundidade & $0.710^{* * *}$ & $0.452^{* * *}$ \\
\hline IDH & 0.001 & $0.000^{*}$ \\
\hline Salário zona urbana & $0.448^{* \star *}$ & $0.676^{* * *}$ \\
\hline Diferencial de salário (urb.-rur.) & -0.037 & $0.462^{\star \star}$ \\
\hline Constante & $0.684^{* \star *}$ & $0.293^{* *}$ \\
\hline$R^{2}$ & 0.35 & 0.792 \\
\hline $\mathrm{F}$ & 17.14 & 104.5 \\
\hline $\mathrm{N}$ & 169 & 205 \\
\hline
\end{tabular}

Fonte: Elaboração dos autores.

Nota: ${ }^{* \star *}$ significativo a $1 \%$ de probabilidade; ${ }^{* *}$ significativo a $5 \%$ de probabilidade. Estimativas robustas.

IDH, mesmo com o sinal esperado, não teve o mesmo impacto do que no modelo rural. Deste modo, nas zonas rurais, a busca por qualidade de vida é de grande importância, seja pela deficiência na educação, empregos, ou salários menores. Em contrapartida, nas zonas urbanas, o efeito da busca por maiores salários é mais forte. Grande parte desse efeito pode ser atribuído à migração rural, que provavelmente está influenciando na importância da variável fecundidade no modelo urbano.

Os resultados econométricos confirmam a hipótese da proposta de análise deste artigo, de que as agregações de AMC comumente empregadas nos trabalhos empíricos geram estatísticas pouco confiáveis. Além de mostrar melhor ajustamento, o modelo de AMC/PV gerou estatísticas condizentes com os pressupostos teóricos, tanto no modelo rural quanto no urbano.

\section{Conclusões}

Este trabalho teve como objetivo propor uma metodologia alternativa para lidar com problemas de Áreas Mínimas Comparáveis com aplicações dos Polígonos de Voronoi e agregação de dados por ponderação. $O$ problema de AMC surge devido aos desmembramentos territoriais dos municípios, que impossibilitam a análise de variáveis socioeconômicas no tempo. O Ipea fornece séries de dados censitários agregados por AMC, no entanto, o método de agregação segue o mesmo princípio de agregação dos territórios, o qual gera viés nos testes estatísticos.

Para testar a eficiência do método aqui proposto, utilizou-se método econométrico de MQO para compará-lo com o método adotado pelo Ipea. $O$ teste econométrico foi aplicado às aglomerações populacionais na Região Norte do Brasil sob pressupostos da Nova Geografia Econômica, analisando a variação populacional entre 1980 e 2000.

Foram construídas 103 AMC pelo método de Polígono de Voronoi e 79 utilizando a metodologia do Ipea. Os dados censitários, que explicam as aglomerações populacionais, foram distribuídos nos dois modelos de AMC. No modelo AMC/Ipea, foi feita a soma e, no AMC/PV, realizou-se a ponderação conforme proposto neste artigo.

O teste comparativo entre os dois modelos mostrou que o AMC/PV gera resultados mais confiáveis e consistentes com a teoria empregada. O modelo AMC/Ipea sugeriu que a variação populacional nas zonas rurais foi impactada negativamente pelas migrações das zonas rurais para as urbanas, pelo IDH e pela mecanização, sendo que esta última não foi significativa. Entretanto, este modelo indicou como positiva a influência da 
variável diferencial de salário iterada com a variável oferta de terras, quando deveria ser negativa. O mesmo ocorreu com a variável concentração de propriedade, que, embora não significativo, apresentou sinal contrário ao esperado. Por outro lado, no modelo AMC/PV, os resultados mostraram-se de acordo com os pressupostos da teoria da NGE. Neste caso, variáveis como a mecanização, concentração de terras e diferencial de salário iteradas com a oferta de terras impactaram negativamente no crescimento da população nas zonas rurais.

Quanto às variações das aglomerações urbanas, a diferença de resultados entre os dois modelos é mais acentuada. No método AMC/Ipea, a variável de maior impacto é a taxa de fecundidade, seguida pela variável salário, que, na realidade, deveria ser a mais expressiva. A migração populacional das zonas rurais para urbanas deveria apresentar sinal positivo, mas ocorreu o contrário. Outra variável que supostamente

\section{Referências}

ANDERSEN, et al. The dynamics of deforestation and economic growth in the brazilian Amazon. Cambridge: Cambridge University Press, 2002.

BAUM, C. F. An introduction to modern econometric using Stata. Texas EUA: Stata press, 2006.

BRASIL, M. C. Os fluxos migratórios na região norte nas décadas de 70 e 80: uma análise exploratória. Cadernos de Estudos Sociais, Recife, v. 13, p. 51-70, 1997.

BRASIL. Ministério da Saúde. Indicadores e Dados Básicos - IDB, 2009. Disponível em: <http://www2.datasus.gov.br/DATASUS > .

BREMAEKER, F. E. J. Ajustamento da base territorial para comparação dos dados dos censos de 1980 e 1991. Base territorial n.12. Rio de Janeiro: Instituto Brasileiro de Administração Municipal - Ibam, 2006.

CHEIN, F. F.; LEMOS, M. B. Proposta de compatibilização da malha municipal dos censos de 70, 80, 91 e 2000. Belo Horizonte, 2004. Mimeografado. deveria ser significativa apresentou sinal contrário ao esperado: o diferencial de salários das zonas urbanas. No modelo $\mathrm{AMC/PV}$, as variáveis salário pago na zona urbana e diferencial de salário entre as duas zonas são as que melhor explicam as aglomerações urbanas. A migração das zonas rurais para urbanas também tem efeito expressivo. Nesse modelo, somente a variável IDH não evidenciou fortes efeitos nas aglomerações.

Ademais, o modelo de AMC/PV apresentou melhor ajustamento dos dados. Com esse desempenho, trabalhos futuros que visem análises espaciais com o uso de Polígonos de Voronoi, seguramente, deverão apresentar resultados mais satisfatórios, haja vista que por esta metodologia os dados são agrupados seguindo a lógica dos efeitos espaciais de vizinhança, além de preservar a quantidade de municípios existentes no período base, melhorando a qualidade das estimações.

CONSIDERA, C. M.; MEDINA, M. H. PIB por unidade da federação: valores correntes e constantes - 1985/96. Rio de Janeiro: Ipea, 1998 (Texto para discussão, 610).

ELLISON, G.; GLAESER, E. The geographic concentration of industry: does natural advantage explain agglomeration? American Economic Review, v. 89, n. 2, p. 311-316, 1999.

FEITOSA, F. F.; MONTEIRO, A. M. V.; CÂMARA, G. Compatibilização de dados censitários para análises temporais com o auxílio de imagens Landsat. In: XII SIMPÓSIO BRASILEIRO DE SENSORIAMENTO REMOTO. Anais... Goiânia, 2005.

FUJITA, M.; KRUGMAN, P.; VENABLES, A. J. Economia espacial. Urbanização, prosperidade econômica e desenvolvimento humano no mundo. São Paulo: Futura, 2002.

GLAESER, E. L. et. al. Economic growth in a cross-section of cities. Journal of Monetary Economics, v. 36, p. 117-143, 1995. 
GLAESER, E. L. Are cities dying? Journal of Economic Perspectives, Nashville, v. 12, n. 2, p. 139-160, 1998

GOLGHER, A. B.; MARQUES, D. H. F. A migração urbano/urbano, rural/urbano, urbano/rural e rural/rural no Brasil: a busca de padrões e de diferenças - implicações para a pobreza rural. In: XII ENCONTRO NACIONAL DE ESTUDOS POPULACIONAIS. Anais... Caxambu, Abep, 2006.

GREENE, W. H. Econometric analysis. 5 ed. New Jersey, EUA: Prentice Hall, 2003.

IBGE - Instituto Brasileiro de Geografia e Estatística. Censo Demográfico 1980. Rio de Janeiro, 1982.

Manual Técnico de Noções Básicas de Cartografia. Rio de Janeiro, 1989. Disponível em: <www. http://www.ibge.gov. br>. Acesso em: 05 jul. 2010.

Censo Demográfico 2000. Rio de Janeiro, 2002. Disponível em: <www. http://www.ibge.gov.br>. Acesso em: 05 jul. 2010.

Contas Regionais do Brasil 2003-2006. Rio de Janeiro, 2008. Disponível em: <www. http://www.ibge.gov.br>. Acesso em: 05 jul. 2010.

Produto Interno Bruto dos Municípios 2003-2006. Rio de Janeiro, 2009. Disponível em: <www. http://www.ibge.gov. br>. Acesso em: 05 jul. 2010.

KOLAHDOUZAN, M. R.; SHAHABI, C. Voronoi-based $\mathrm{K}$ nearest neighbor search for spatial network databases. In: VLDB, 2004. Proceedings of the 30th VLDB Conference. Toronto, Canada, 2004.

LLOYD, C. D. Local models for spatial analysis. Boca Raton: Taylor \& Francis Group, 2007.

MARTINS, C. M.; ALMEIDA, F. A. Fecundidade paulistana: diferenciais de escolaridade e desenvolvimento humano (IDH). In: XII ENCONTRO NACIONAL DE ESTUDOS POPULACIONAIS. Anais... Caxambu, Abep, 2000.

MONMONIER, M. Cartographies of danger: mapping hazards in America. Chicago: University of Chicago Press, 1997.

MOREIRA, M. de M. Envelhecimento da população brasileira: aspectos gerais. In:
WONG, L. R. (Org.). O envelhecimento da população brasileira e o aumento da longevidade - subsídios para políticas orientadas ao bem-estar do idoso. Belo Horizonte: UFMG/Cedeplar, Abep, 2001.

OKABE, A.; BOOTS, B.; SUGIHARA, K. Spatial tessellations: concepts and applicaions of Voronoi diagrams. John Wiley and Sons, 1992.

OLIVEIRA, A. T.; SIMÕES, A. G. Deslocamentos populacionais no Brasil: uma análise dos censos demográficos de 1991 e 2000. In: XIV ENCONTRO NACIONAL DE ESTUDOS POPULACIONAIS. Anais... Caxambu, Abep, 2004.

PAIVA, C. A. Uma alternativa à metodologia das AMCs. RMSD, 2007. Disponível em: <http://www.fee.tche.br>. Acesso em: 18 maio 2010.

(Org.). Evolução das desigualdades territoriais no Rio Grande do Sul. Santa Cruz do Sul: Edunisc, 2008.

PARTRIDGE, M.; OLFERT, M. R.; ALASIA, A. Canadian cities as regional engines of growth: agglomeration and amenities. Canadian Journal of Economics, v. 40, n. 1, p. 39-68, 2007.

REIS, E.; PIMENTEL, M.; ALVARENGA, A. I. Áreas mínimas comparáveis para os períodos intercensitários de 1872 a 2000. Rio de Janeiro: Ipea/Dimac, 2008. Mimeografado.

SILVA, A. B. O.; MEDINA, M. H. Produto Interno Bruto por unidade da federação - 1985/98. Brasília: Ipea, 1999 (Texto para discussão, 677)

SILVA, R. R. Pobreza no Estado do Amazonas: uma análise espacial. In: VII ENABER. Anais... São Paulo, 2009.

SOUZA, C. C. A. A Nova Geografia Econômica: três ensaios para o Brasil. Tese (Doutorado em economia). Belo Horizonte, UFMG, 2007.

UMBELINO, G.; BARBIERI, A. Metodologia para a compatibilização de setores censitários e perímetros urbanos entre os censos de 1991, 2000 e 2010. In: XV ENCONTRO NACIONAL DE ESTUDOS POPULACIONAIS. Anais... Caxambu, 2008. 


\title{
Resumen
}

Polígonos de Voronoi como alternativa a los problemas de las Áreas Mínimas Comparables: un análisis de los cambios poblacionales en la región norte de Brasil

Este artículo propone una metodología alternativa para la construcción de Áreas Mínimas Comparables, en lo sucesivo AMC, y un método de ponderación de variables socioeconómicas para esas AMC. El análisis empírico, en particular en el área de economía, de los cambios poblacionales, económicos y sociales en el nivel municipal es una tarea razonablemente compleja. Esto se produce debido a la constante formación de distritos a partir del desmembramiento de otros municipios. El método de agregación utilizado habitualmente sigue la misma lógica de división territorial, que genera sesgos en los tests estadísticos. En este trabajo, se propone un método alternativo de construcción de AMC, aplicando los Polígonos de Voronoi, en adelante PV, y agregando datos por ponderación. Para comprobar el método propuesto, se evaluaron los cambios poblacionales ocurridos en la región norte entre 1980 y 2000, a la luz de la Nueva Geografía Económica, en adelante NGE, comparándolo con el método de AMC adoptado por el Ipea. El modelo de AMC con PV presentó un mejor ajuste de datos y coherencia en el comportamiento de las variables, de acuerdo con la teoría. Con este desempeño, los futuros trabajos que tengan por objeto análisis espaciales con el uso de $\mathrm{PV}$, seguramente, deberán presentar resultados más satisfactorios, considerando que por esta metodología los datos se agrupan siguiendo la lógica de los efectos espaciales por semejanza.

Palavras-chave: Polígonos de Voronoi. Áreas Mínimas Comparables. Análisis espacial.

\begin{abstract}
Voronoi poligons as an alternative for problems in minimum comparable areas: an analysis of demographic changes in Northern Brazil
\end{abstract}

This article presents an alternative methodology for constructing minimum comparable areas (MCAs) and a method for weighting socioeconomic variables for such MCAs. Empirical analysis - especially in the area of economics - of demographic, economic and social changes at the municipal level is a reasonably complex task. This is so because of the constant creation of new districts produced by the division of present municipalities. The method of aggregation normally used follows the same logic of territorial division, which generates biases in statistical tests. In this article the authors propose an alternative method for constructing MCAs by applying Voronoi polygons and aggregating the data by weighting. To test the method proposed, demographic changes that took place in the Northern Region of Brazil between 1980 and 2000 were evaluated in the light of New Economic Geography (NEG), comparing it with the MCA method adopted by IPEA. The MCA model with Voronoi polygons showed the best adjustment of the data and consistency regarding the behavior of the variables according to the theory. With this performance, further research aimed at carrying out spatial analyses with the use of Voronoi polygons will most likely present more satisfactory results since, by means of this methodology, the data is grouped according to the logic of neighboring spatial effects.

Keywords: Voronoi polygons. Minimum comparable areas. Spatial analysis. 